\title{
CONCORRÊNCIA E AS PARTICIPAÇÕES MINORITÁRIAS ENTRE FIRMAS RIVAIS
}

\author{
Carolina Policarpo Garcia * \\ Elizabeth M.M.Q. FARINA ${ }^{\dagger}$
}

\begin{abstract}
Resumo
O objetivo deste trabalho é analisar quais os impactos sobre a concorrência de participações minoritárias entre firmas rivais. A aplicação do $M H H I$, índice de concentração recentemente proposto na literatura, indica que essas ligações estruturais podem causar efeitos adversos sobre a concorrência. Tais prejuízos se intensificam quanto maiores os marketshares e o poder de controle que a firma adquirente tem sobre a adquirida. Porém, quando essas ligações são ignoradas ou consideradas como fusões completas, tais prejuízos são subestimados ou superestimados, respectivamente. Assim, conclui-se que o MHHI é um indicador de concentração mais adequado na presença de participações minoritárias entre firmas rivais.
\end{abstract}

Palavras-chave: Concorrência; Índices de Concentração; Participações Minoritárias.

\begin{abstract}
The objective of this paper is to analyze the impacts of minority shareholdings among rival firms on competition. The application of MHHI (Modified Herfindahl Hirschman Index), a measure of market concentration recently proposed in the literature, shows that these structural links may cause adverse effects on competition. Such losses are intensified with increasing market-shares and the controlling power that the acquiring firm has on the acquired one. However when these links are ignored or taken as full mergers, such losses are underestimated or overestimated, respectively. Therefore we conclude that the MHHI would be the most adequate measure of market concentration in the presence of minority shareholdings among rival firms.
\end{abstract}

Keywords: Competition; Index of Concentration; Minority Shareholdings.

JEL classification: D, D21, L1, L4

\footnotetext{
* EESP FGV. E-mail: carolina.garcia@gvmail.br

† FEA USP. E-mail: emmqfari@usp.br
} 


\section{Introdução}

Este trabalho tem como objeto o estudo da aquisição de participações minoritárias entre firmas rivais e suas consequências para a concorrência nos mercados afetados. Em todo o mundo observa-se um rápido crescimento de aquisições de participações minoritárias entre firmas rivais. As principais perguntas que as autoridades de defesa da concorrência têm se colocado são: participações minoritárias entre firmas rivais podem gerar efeitos nocivos às práticas competitivas de mercado? Como avaliar esses efeitos?

Um indicador importante de concentração e que é largamente utilizado é o Índice de Herfindahl-Hirschman (HHI). Este trabalho utilizou uma adaptação deste indicador que leva em conta participações minoritárias e que foi proposta recentemente na literatura. Os efeitos da aquisição de participação minoritária em empresa rival dependem do poder de decisão que o minoritário obtém. Portanto, o elemento fundamental para a análise está na compreensão das mudanças de governança.

O setor de produção de concreto da região Sul do Brasil, que vem sofrendo um processo de rápida concentração por meio de fusões e aquisições, ilustra bem as participações cruzadas entre empresas, por meio de participações minoritárias. Dessa forma as operações nesse mercado servirão como exemplo da discussão desenvolvida no trabalho. A ideia é identificar se a adoção do MHHI traria resultados diversos dos obtidos nesses casos de atos de concentração.

Além desta introdução, este artigo está estruturado como segue. A seção 2 apresenta a revisão da literatura sobre o tema, explicitando como surgem os problemas anticompetitivos que podem advir das participações minoritárias entre rivais. A seção 3 faz um resumo das operações envolvendo participações minoritárias ocorridas no setor de produção de concreto da região Sul do Brasil. A seção 4 apresenta os resultados dos cálculos dos índices de concentração para o setor. A seção 5 finaliza o trabalho.

\section{Revisão da Literatura}

Uma participação minoritária refere-se ao caso em que um acionista detém menos de $50 \%$ dos direitos de voto de uma companhia ou, de forma mais geral, detém uma quantidade não expressiva em termos de controle acionário (Organization for Economic Co-operation and Development 2008, p. 4). À primeira vista, essas participações parecem inofensivas de uma perspectiva competitiva. No entanto, estudos econômicos recentes alertam para o fato de que, quando o investimento é realizado entre firmas competidoras, essa integração parcial pode restringir a competição entre as firmas assim estruturadas e resultar em efeitos negativos sobre a concorrência.

Não parece óbvio definir essas transações envolvendo participações minoritárias como fusões completas se os tomadores de decisão das firmas mantiverem alguma independência. Também não parece óbvio estabelecer o mercado como competição perfeita após a transação, já que a participação minoritária pode afetar os incentivos dos proprietários.

A intuição pode sugerir que uma participação minoritária é menos problemática do ponto de vista competitivo do que uma fusão completa, dado que as partes podem continuar competindo após a transação. Contudo, essa intuição não é sempre correta. O’Brien \& Salop (2000) mostraram que essa integração 
parcial pode ocasionar prejuízos à concorrência maiores ou menores do que nos casos de fusões completas. Essa conclusão parece surpreendente, dado que uma participação minoritária parece alinhar menos os interesses das partes do que no caso de uma fusão completa.

Os efeitos competitivos da aquisição de participação minoritária em empresa rival dependem do poder de controle que o minoritário obtém. O grau de controle determina a capacidade que o acionista tem de interferir nas decisões estratégicas da firma em que tem participação. Quanto maior o controle maior a probabilidade de alinhamento das estratégias das firmas e, consequentemente, maiores os prejuízos à concorrência. Portanto, o elemento fundamental para a análise está na compreensão das estruturas de governança.

\subsection{Fundamentos de organização industrial}

O Sistema Brasileiro de Defesa da Concorrência (SBDC) adota um sistema de controle de atos de concentração econômica por meio da Lei 12.529/2011. A abordagem tradicional para análise dos atos de concentração está centrada na metodologia estrutura-conduta-desempenho, que estabelece que a estrutura de mercado determina a conduta das firmas, que por sua vez determina o desempenho do mercado. Como essa relação causal é considerada estável, há ligação direta entre estrutura e desempenho, cujas variáveis são mais facilmente observáveis (Church \& Ware 2000, p. 425).

Essa abordagem seria a base do Guia para Análise dos Atos de Concentração Horizontal no Brasil, adotado pela Secretaria de Acompanhamento Econômico (Seae) e pela Secretaria de Desenvolvimento Econômico (SDE) em 2002 (Farina \& Nunes 2006, p. 49), de modo que a concentração tem papel fundamental na análise dos casos, mesmo considerando os possíveis ganhos de eficiência pós-fusão.

Cowling \& Waterson (1976) derivaram um modelo que explicita essa relação entre estrutura e desempenho, relacionando mudanças na relação entre margem e preço a mudanças na concentração. Esse resultado corrobora a visão estrutural de que maior concentração resulta em maior poder de mercado, o que justificaria o estabelecimento de níveis de concentração que demarcassem a probabilidade do exercício de poder de mercado, como ocorre no Guia para Análise dos Atos de Concentração Horizontal no Brasil.

O Índice de Herfindahl-Hirschman (HHI) é um índice amplamente aceito como medida de concentração. Ele é calculado pela soma dos quadrados das participações de mercado de cada uma das firmas da indústria. O HHI leva em consideração o tamanho relativo e a distribuição das firmas no mercado. $\mathrm{O}$ índice se aproxima de zero quando o mercado é fragmentado. O HHI aumenta tanto quando o número de empresas no mercado diminui, como quando a disparidade de participação de mercado entre essas empresas aumenta.

$$
H H I=\sum_{i=1}^{n} s_{i}^{2}
$$

Por outro lado, a abordagem "moderna" da análise dos atos de concentração refere-se à adoção de modelos de oligopólio que incorporam diversas formas de interdependência entre rivais, ao invés de uma análise fortemente 
dependente da análise da concentração. Nesse caso, as fusões devem ser analisadas dentro de uma perspectiva de equilíbrios de mercado (Farina \& Nunes 2006, p. 50).

Com base no modelo de Cournot e produtos homogêneos, Farrell \& Shapiro (1990) mostraram que a mudança no HHI varia na direção correta da mudança de bem-estar, se não houver ganhos de eficiência entre as firmas fusionadas. Os autores mostraram também que a quantidade produzida pela firma fusionada será menor e a quantidade da não fusionada será maior.

Esses resultados corroboram o fato de que, embora fatores como rivalidade, entrada e inovação devam ser considerados nas análises de fusões, o nível de concentração continua desempenhando um papel central no antitruste. Assim, fundamenta-se a utilização de índices de concentração, tal como o HHI, para avaliar os possíveis efeitos de uma fusão.

\subsection{Distinção entre interesse financeiro e controle corporativo}

Visando avaliar quais os possíveis efeitos anticompetitivos das participações minoritárias, O’Brien \& Salop (2000, p. 562) argumentam que tais efeitos dependem de dois elementos distintos: interesse financeiro e controle corporativo. O interesse financeiro se refere ao direito de receber uma parcela dos lucros da firma em que tem participação. Controle corporativo se refere à habilidade de controlar ou influenciar as decisões competitivas da firma, incluindo preços e produção bem como a oferta de ações da companhia.

Nas estruturas em que estão presentes as participações minoritárias, não necessariamente o agente que tem o interesse financeiro possui também o controle corporativo. Considere, por exemplo, uma firma com apenas dois acionistas, um com participação de $51 \%$ e o outro com participação de $49 \%$. Embora a parcela dos lucros dos dois agentes seja praticamente a mesma, o acionista majoritário pode ter total controle sobre as decisões. Isso pode não fazer diferença se os interesses dos dois acionistas estão perfeitamente alinhados, mas seguramente faz se os interesses não estão alinhados por alguma razão.

Geralmente, um grande interesse financeiro vem acompanhado de um grande controle corporativo. Isso é certamente verdade quando comparamos indivíduos com participações majoritárias e minoritárias. Quando não há um acionista majoritário, os maiores acionistas minoritários podem ter um controle desproporcional, como resultado, por exemplo, da sua habilidade de formar coalizões de voto que podem controlar as estratégias.

No mundo moderno, as corporações apresentam estruturas financeira e corporativa bastante complexas, em que há, por exemplo, distinção entre ações com e sem direito a voto. No caso de ações sem direito a voto, o acionista tem o interesse financeiro, mas não o controle corporativo. Essa estrutura pode conduzir a uma situação em que o acionista com minoritário interesse financeiro controla a firma. A emissão de múltiplas classes de ações que diferem no poder de voto contribui para que acionistas minoritários tenham controle, por exemplo. 


\subsection{Condutas unilaterais e coordenadas}

A despeito do ceticismo de Areeda \& Turner (1980), que concluíram que uma "aquisição sem controle não tem perigo intrínseco à concorrência"1 (tradução própria), posteriormente, uma série de outros autores, tais como Reynolds \& Snapp (1986), Bresnahan \& Salop (1986), O’Brien \& Salop (2000), Ezrachi \& Gilo (2006) entre outros e, inclusive, entidades governamentais, tal como a Organization for Economic Co-operation and Development (2008), mostraramse não somente preocupados com os possíveis efeitos sobre a concorrência das participações minoritárias como alguns também provaram a existência de tais efeitos em determinadas condições. ${ }^{2}$

Os incentivos para condutas anticompetitivas podem ser unilaterais ou coordenados, e surgem, principalmente, devido à transparência de informações estratégicas advindas da estrutura gerada pela participação minoritária.

No caso de ações unilaterais, o minoritário utiliza as informações adquiridas da firma em que tem participação para adequar suas estratégias de mercado de acordo com a estratégia adotada pela firma rival. No entanto, ainda que a firma adquirente não obtenha informações estratégicas da firma adquirida, ela terá incentivos para mudar suas estratégias devido à correlação positiva entre os lucros das duas firmas.

Ações coordenadas podem surgir, principalmente, se a estrutura incorrer em participações cruzadas. A cooperação pode ser alcançada através da troca de informações sobre preços, custos e outras estratégias comerciais.

Tanto no caso das ações unilaterais como no caso de ações coordenadas os possíveis resultados são o aumento dos preços e/ou a redução da produção, além do risco de redução da qualidade, da variedade e do incentivo às inovações. Tais resultados implicam sempre redução do bem-estar econômico. ${ }^{3}$

\section{Incentivos econômicos para as condutas unilaterais}

Nos mercados com competição imperfeita, a decisão de uma firma acerca de um aumento de preço deve ser avaliada em termos dos custos e benefícios do aumento. O custo do aumento de preço deriva do fato de que alguns consumidores deixarão de comprar o produto, ou o consumirão em menor quantidade, e os lucros dessas vendas serão perdidos. O efeito benéfico desse aumento de preço é que as vendas restantes contribuirão com uma parcela maior nos lucros. O efeito líquido nos lucros de um aumento de preços é a soma desses dois resultados.

Esses incentivos mudam quando uma firma adquire um concorrente ou parte dele (doravante denominados firmas "adquirente" e "adquirida"). Quando a firma adquirente opta pelo aumento de preço na sua própria firma, algumas das vendas perdidas serão desviadas para a firma adquirida, de modo que ela recupera parte dos lucros que havia perdido devido ao aumento do preço. É importante destacar que o incentivo unilateral que a firma adquirente tem para aumentar o preço não requer que ela tenha controle sobre a firma adquirida. O aumento unilateral de preço deriva simplesmente do interesse financeiro na firma adquirida, de modo que quanto maior o interesse

\footnotetext{
${ }^{1}$ Areeda \& Turner (1980, p.322) apud O’Brien \& Salop (2000, p.562).

${ }^{2}$ Grande parte desta subseção está baseada no trabalho de O’Brien \& Salop (2000)

${ }^{3}$ Se não houver barreiras insuperáveis à entrada de novos competidores os efeitos serão de curto prazo.
} 
financeiro na firma adquirida maior o incentivo que a adquirente tem para aumentar o preço.

Quando a firma adquirente também tem o controle corporativo sobre a adquirida, os incentivos unilaterais da firma adquirida também mudam. De modo análogo aos incentivos da firma adquirente, quando a firma adquirida aumenta preço, algumas vendas serão desviadas para a adquirente, que aumentará seus lucros. Se a firma adquirente controla a adquirida, ela levará em conta esse acréscimo no lucro no momento da escolha do preço da firma adquirida.

O tamanho dos incentivos que a firma adquirida tem para aumentar o preço depende da sua estrutura de governança, em particular, do grau de controle que a firma adquirente tem sobre a firma adquirida. O grau de controle não é necessariamente proporcional ao interesse financeiro. Como mencionado anteriormente, um acionista com $49 \%$ de ações com direito a voto não tem controle frente a um acionista com $51 \%$ de ações com direito a voto. Mas um acionista com $25 \%$ de ações com direito a voto pode ter controle efetivo se todos os outros acionistas têm apenas $1 \%$ cada.

O grau de controle também é significativamente afetado pela estrutura de governança da firma adquirida e pelas restrições impostas pelas leis empresariais na jurisdição relevante. Por esse motivo, as análises envolvendo participações minoritárias devem estar atentas às estruturas de governança.

\section{Incentivos econômicos para ações coordenadas}

Uma outra questão que advém das participações minoritárias é que essas ligações estruturais podem facilitar ações coordenadas. A existência dessas ligações não é condição suficiente para concluir que a colusão é um provável resultado no mercado, no entanto, é necessário atentar para essas ligações estruturais em termos de incentivos e oportunidades para a coordenação.

Primeiramente, para que um acordo de coordenação seja bem sucedido, a teoria econômica elenca três condições: (1) há concordância entre os participantes em relação aos termos do acordo; (2) as condições de mercado devem ser transparentes a fim de que cada membro do cartel possa monitorar os demais participantes; (3) a implementação de uma punição em caso de desvio de conduta deve ser crível.

Variáveis estruturais e de mercado também podem afetar as condições de implementação e estabilidade da coordenação, tais como número de competidores, barreiras à entrada, repetição da interação, grau de homogeneidade dos produtos e das firmas, elasticidade-preço da demanda e muitos outros fatores.

A participação minoritária é um fator estrutural que pode proporcionar ao seu proprietário acesso à informações estratégicas da firma adquirida. Essas informações podem facilitar a colusão e o monitoramento da aderência a uma conduta comum adotada. Se a participação minoritária é recíproca e interliga todos os competidores no mercado, a troca de informações e a possibilidade de coordenação aumentam substancialmente.

O grau de transparência no acesso às informações depende dos direitos associados àquela participação minoritária. Se a participação confere à firma adquirente direitos de controle, tal como apontar membros da mesa diretora ou de cargos executivos estratégicos da firma adquirida, o grau de transparência é alto. No entanto, ainda que a participação na rival seja apenas com interesse financeiro, sem nenhum controle, o acionista pode ter acesso a informações 
estratégicas. Essa transparência de informações pode facilitar a coordenação entre as firmas.

Outro fator facilitador do compartilhamento de informações pode ser a presença dos chamados "interlocking directorates", como conhecidos na literatura internacional. A expressão diz respeito à presença de administradores, conselheiros ou, de alguma maneira, participantes de decisões estratégicas comuns a duas ou mais firmas que, do mesmo modo, têm acesso a importantes informações das firmas. Essa prática levanta questões acerca da qualidade e da independência da tomada de decisão nas firmas interligadas.

O que ocorre na maioria dos casos é um controle parcial, em que o proprietário obtém informações gerenciais e pode influenciar nas decisões estratégicas comerciais da firma em que tem participação e, ao mesmo tempo levar essa informação para a sua firma, aumentando a probabilidade de ação coordenada. A questão é que, mesmo nos casos de simples investimento financeiro, tal estrutura pode gerar transparência de informações relevantes do ponto de vista competitivo entre as firmas ligadas.

\subsection{Participações minoritárias: como mensurar o problema?}

Um dos primeiros trabalhos com foco na questão dos efeitos competitivos causados por participações minoritárias entre competidores foi o de Reynolds \& Snapp (1986). Os autores apontaram que mesmo participações minoritárias relativamente pequenas podem causar efeitos competitivos substanciais, de modo que as autoridades antitruste devem examinar o trade-off entre aumentos de eficiência e redução da competitividade também nesses casos.

Os resultados do trabalho de Reynolds \& Snapp (1986) apontam que as ligações estruturais mudam as funções de reação das firmas envolvidas, enquanto as funções de reação das outras firmas não mudam. O efeito da produção no tempo depende das condições de barreiras à entrada. Se a entrada é rápida e fácil, os altos lucros da produção reduzida no mercado podem atrair novas firmas e eliminar os ganhos obtidos. Se existem barreiras à entrada ou se a entrada é um processo lento e difícil, o valor presente dos ganhos gerados pelas ligações estruturais pode ser significativamente positivo.

A existência de efeitos estruturais causados por participações minoritárias indica que o cálculo de indicadores convencionais de concentração que ignoram essas ligações podem não refletir adequadamente o estado de competição dos mercados.

Areeda \& Turner (1980, p.322) ${ }^{4}$ concluíram ser impossível a derivação de métodos quantitativos, como índices de concentração, que levam em conta participações minoritárias. Posteriormente, com o intuito de atender a essa condição, Bresnahan \& Salop (1986) desenvolveram um HHI ajustado, que reflete os efeitos dessas ligações estruturais.

\section{O MHHI — Modified Herfindahl-Hirschman Index}

$\mathrm{O} M H H I$, assim como o $H H I$, assume que as firmas competem segundo um modelo de Cournot. Suponha que $\beta_{i j}$ é a fração da firma $j$ que pertence ao proprietário $i$, de modo que $\sum_{i} \beta_{i j}=1$ para cada firma $j$. Além disso, suponha que $\gamma_{i j}$ é o peso que o lucro do proprietário $i$ tem quando a firma $j$ resolve

\footnotetext{
${ }^{4}$ Areeda \& Turner (1980, p.322) apud O’Brien \& Salop (2000, p.322).
} 
o seu problema de maximização ( $\gamma_{i j}$ é um fator que mostra qual o grau de controle que o proprietário $i$ exerce sobre a firma $j$ ), de modo que $\sum_{i} \gamma_{i j}=1$ para cada firma $j$. A participação de mercado da firma $j$ é $s_{j}$.

O MHHI pode ser expresso pela seguinte equação:

$$
M H H I=H H I+\sum_{j} \sum_{k \neq j}\left(\frac{\sum_{i} \gamma_{i j} \beta_{i k}}{\sum_{i} \gamma_{i j} \beta_{i j}}\right) s_{k} s_{j}
$$

em que o segundo termo da equação é o $\triangle M H H I$.

A partir da equação (2), observamos que o $M H H I$ é uma extensão do $H H I$. O MHHI soma ao HHI um termo que reflete a concentração de mercado levando em consideração participações cruzadas, ponderado pelas participações das firmas no mercado.

A análise da variação do $M H H I$ pré e pós-transação pode oferecer alguma orientação para avaliar se a aquisição de participações minoritárias causa impactos nos incentivos que as firmas têm para competir, dada certa estrutura de mercado e certa estrutura corporativa. Contudo, Dubrow (2001, p. 130) afirma que essa metodologia é preditiva na melhor das hipóteses, e não pode ser invocada para afirmar que uma determinada transação é irá resultar em redução significativa da concorrência. Por outro lado, as limitações e a conveniência do índice foram apresentadas por O’Brien \& Salop (2000, p. 596-597):

“...o cálculo do MHHI, assim como o HHI, é muito grosseiro ao assumir um mercado relevante, o que implica que não admite substituição por produtos que estejam fora desse mercado, barreiras à entrada insuperáveis, nenhum outro efeito competitivo e ausência de ganhos de eficiência. Contudo, os cálculos podem ser úteis como um primeiro passo, assim como o HHI em análises de fusões."(tradução própria)

A análise dos efeitos anticompetitivos através do $\mathrm{MHHI}$ se sustenta sob a hipótese de que não há formação de conluio entre as firmas, isto é, as firmas competem entre si e escolhem preços de forma independente e unilateral. $\mathrm{O}$ foco está nos incentivos unilaterais e a hipótese de não cooperação entre as firmas se mantém mesmo depois da ligação estrutural.

Mensuração do grau de controle do proprietário: índices de poder

Como visto na seção anterior, para obtermos a medida correta da concentração na presença de participações cruzadas através do $M H H I$, precisamos de uma medida do grau de controle de cada acionista em cada firma em que tem participação.

A literatura de Governança Corporativa que mensura o poder de controle dos acionistas de uma determinada firma tem utilizado os índices de poder da Teoria dos Jogos para inferir o grau de controle desses acionistas. Um índice de poder mensura a influência relativa de cada participante do jogo durante a tomada de decisão, no sentido de sua capacidade de usar seu voto para mudar uma coalizão que era perdedora para uma que satisfaz o requisito da maioria e ganha. O número de vezes que um membro pode fazer isso é expressado em termos da proporção em relação ao número de resultados possíveis do jogo de votação, sendo os resultados aleatórios e igualmente prováveis. Os índices 
clássicos utilizados para tanto são o índice de Shapley-Shubick e o índice de Banzhaf.

Tanto o índice de Shapley-Shubick como o índice de Banzhaf mensuram a habilidade que cada membro tem de mudar uma coalizão de jogadores perdedora para uma coalizão vencedora, a única diferença é o modo como as coalizões são contadas. O índice de Shapley-Shubick é calculado contando as ordenações de jogadores, enquanto o índice de Banzhaf conta as coalizões possíveis, independentemente da ordem dos jogadores na coalizão. Essa característica do índice de Banzhaf o coloca como o mais adequado para descrever grande parte das situações reais de jogos de votação.

Leech (2002) calculou os índices de poder de Shapley-Shubick e Banzhaf para os acionistas em uma grande amostra de empresas britânicas e os testou contra critérios em termos de como provavelmente deveriam se comportar os índices dadas as variações de padrões de propriedade entre as empresas. Os resultados não deram qualquer razão para que o índice de Banzhaf fosse rejeitado, no entanto o índice de Shapley-Shubick não satisfez ao critério. $O$ artigo conclui que o índice de Shapley-Shubick não é uma medida adequada nesse caso.

Além disso, Trivieri (2005) faz uma aplicação do MHHI para o setor bancário italiano e, seguindo Leech (2002), utiliza o índice de poder de Banzhaf para determinar o grau de controle dos acionistas. Assim, o presente trabalho considera o índice de poder de Banzhaf o mais adequado para determinar o grau de controle dos acionistas.

Para definir o índice de Banzhaf formalmente, suponha que uma empresa tem $N$ acionistas (jogadores), cada um deles detentor de uma cota proprietária (voting weight) $w_{i}$ com $i=1, \ldots, n$ de modo que $0<w_{i}<0,5^{5}$ e $\sum_{i} w_{i}=1$. Seja $q$ a cota que identifica a regra de decisão do processo de votação, no nosso caso a regra da maioria, de modo que $q=0,51$. Seja $T \subseteq N$ uma coalizão de acionistas com $w(T)=\sum_{i \in T} w_{i}$. A coalizão $T$ é vencedora se $w(T) \geq q$ e é perdedora se $w(T)<q$. O acionista $i$ é definido crítico para uma coalizão $T_{i}$ se essa coalizão é vencedora com $i$ e perdedora quando $i$ está fora da coalizão, ou seja, se $T_{i}+\{i\}$ é vencedora e $T_{i}$ é perdedora. A representação matemática dess jogo é dada por $\left[q ; w_{1}, w_{2}, \ldots, w_{n}\right]$.

Exitem $2^{n-1}$ diferentes coalizões das quais um jogador pode participar, e $\eta_{i}$ é o número de vezes que o jogador $i$ é crítico para uma coalizão. O índice absoluto de Banzhaf para cada jogador $\left(B_{i}\right)$ é igual à probabilidade dele ser crítico: $B_{i}=\frac{\eta_{i}}{2^{n-1}}$. Para realizar comparações, o índice é normalizado: $\beta_{i}=$ $\frac{\eta_{i}}{\sum_{i} \eta_{i}}$

\section{Participações cruzadas no setor de produção de concreto da região Sul do Brasil}

O setor de produção de concreto $^{6}$ da região Sul do Brasil vem passando por um processo de reestruturação desde o final da década de 90, haja vista o

\footnotetext{
${ }^{5}$ Se algum acionista detiver uma cota maior do que 0,5 ele será o controlador da empresa e não será necessário calcular o índice de poder.

${ }^{6} \mathrm{O}$ serviço de concretagem refere-se ao concreto dosado em central. Este produto, além de ser produzido pelas concreteiras mecanicamente, deve seguir determinadas especificações técnicas e controles de qualidade. Inclui-se ao serviço de concretagem o transporte das misturas em caminhões-betoneiras e o seu lançamento na obra.
} 
grande número de Atos de Concentração (A.C.) submetidos ao Sistema Brasileiro de Defesa da Concorrência (SBDC). Os meios através dos quais essas mudanças ocorreram foram aquisição de participações, aquisição do controle de concreteiras estabelecidas ou de alguns ativos físicos dessas concreteiras em determinados lugares. A região onde houve maior concentração de mercado foi a região Sul do país.

\subsection{Seleção dos atos de concentração}

A pesquisa dos atos de concentração do setor de produção de concreto da região Sul do Brasil foi realizada através do site do CADE (Conselho Administrativo de Defesa Econômica). No referido site, há uma seção para pesquisa de processos, sejam eles já arquivados ou em andamento, analisados pelo órgão.

Após esse procedimento de busca, os atos de concentração do setor de produção de concreto da região Sul do Brasil selecionados encontram-se na Tabela 1 a seguir.

Tabela 1: Atos de concentração selecionados para análise

\begin{tabular}{|c|c|c|}
\hline Processo & A.C. $n^{o}$ & Descrição \\
\hline 1 & 08012.007680/1998-51 & $\begin{array}{l}\text { Cia. de Cimento Portland Itaú, cujos acio- } \\
\text { nistas são o Grupo Votorantim }(70,90 \%) \text { e o } \\
\text { Grupo Real }(19,73 \%) \text {, compra } 25 \% \text { da Geral } \\
\text { de Concreto (Votorantim entra no mercado } \\
\text { de concreto) }\end{array}$ \\
\hline 2 & 08012.007704/1999-07 & $\begin{array}{l}\text { Cia. de Cimento Portland Itaú, cujos acio- } \\
\text { nistas são o Grupo Votorantim }(70,97 \%) \text { e } \\
\text { o Grupo Real }(27,32 \%) \text {, compra } 25 \% \text { da Su- } \\
\text { permix. }\end{array}$ \\
\hline 3 & $08012.001227 / 2002-15$ & $\begin{array}{l}\text { Sita-Concrebrás, empresa da Sirama Partici- } \\
\text { pações, cujo maior acionista é o Grupo Vo- } \\
\text { torantim }(38 \%) \text {, compra plantas e ativos de } \\
\text { concretagem da Concrebrás. }\end{array}$ \\
\hline 4 & $08012.000720 / 2002-18$ & $\begin{array}{l}\text { Cimefor, empresa do Grupo Votorantim, } \\
\text { compra a totalidade das ações da Geral de } \\
\text { Concreto. }\end{array}$ \\
\hline 5 & $08012.008848 / 2005-72$ & $\begin{array}{l}\text { Silcar, empresa do Grupo Votorantim, com- } \\
\text { pra } 25 \% \text { da Polimix. }\end{array}$ \\
\hline
\end{tabular}

Existem inúmeros outros processos que não envolvem participações minoritárias e que foram utilizados no estudo. Entre uma aquisição de participação minoritária e outra, ocorrem outras operações, como compra de ativos de serviços de concretagem entre as empresas do setor, que mudam as condições estruturais do mercado e que devem ser levadas em conta na análise. Isso ocorre porque o cálculo dos índices de concentração exige tanto as participações minoritárias entre as empresas como também as participações de mercado de todas as empresas participantes do mercado, que mudam conforme ocorre qualquer tipo de ato de concentração, independentemente da existência de participações minoritárias. 


\subsection{Descrição detalhada dos atos de concentração}

- Cia. de Cimento Portland Itaú (Itaú) e Geral de Concreto (08012.007680/1998-51)

A Cia. de Cimento Portland Itaú (Itaú) é uma empresa do Grupo Itaú, resultado da associação dos grupos Votorantim e Real. A Itaú atua no setor de minerais não metálicos, exclusivamente na produção de cimento e cal. Tem como acionistas a Votorantim Cimentos Ltda. (70,90\%) e o Banco Real de Investimentos (19,73\%).

A Geral de Concreto é uma empresa de participações que controla as empresas Engemix S.A., Concrelix S.A., Engenharia de Concreto e Concremaster Concreto Ltda., todas atuantes no setor de construção civil, na área de serviços de concretagem e lançamento de concreto. A empresa era controlada integralmente pelo Grupo Rossi, formado pela Rossi Participações Ltda. e Rossi S.A.

A operação consiste na aquisição de $25 \%$ do capital votante e total da sociedade Geral de Concreto S.A. pela Cia. de Cimento Portland Itaú. Pelo acordo de acionistas celebrado entre as partes, o conselho de administração da Geral de Concreto será composto por 7 membros, tendo o Grupo Rossi direito a indicar 4 membros e a Itaú os outros 3.

A operação foi apresentada ao SBDC em 09/10/1998, julgada em 14/04/1999 e aprovada sem restrições.

- Cia. de Cimento Portland Itaú e Supermix (08012.007704/1999-07)

A Cia. de Cimento Portland Itaú é uma empresa do Grupo Itaú, resultado da associação dos grupos Votorantim e Real, conforme descrito anteriormente. A Itaú tem como acionistas a Votorantim Cimentos Ltda. $(70,97 \%)$ e o Banco Real de Investimentos $(27,32 \%)$. O Grupo Votorantim atua indiretamente no mercado de concreto através da participação de $25 \%$ na Engemix Participações S.A. (operação descrita anteriormente). A Engemix, por sua vez, controla a Geral de Concreto S.A., Concrelix S.A. e Concremaster S.A., prestadoras de serviços de concretagem.

A Supermix Concreto S.A. é uma empresa controlada pelas empresas Soton e Prana, cada uma com 52,23\% e 47,67\% do capital da Supermix, respectivamente.

A operação refere-se à aquisição pela Itaú de $25 \%$ do capital social da Supermix, de modo que após a operação os acionistas desta última sejam as empresas Soton $(39,20 \%)$, Prana $(35,80 \%)$ e Itaú $(25 \%)$. Segundo o acordo de acionistas celebrado entre as partes, o conselho de administração da Supermix será composto por 7 membros, sendo que Soton e Prana indicam juntas 4 conselheiros e a Itaú os outros 3.

A operação foi apresentada ao SBDC em 23/08/1999, julgada em 06/11/2002 e aprovada sem restrições.

- Sita-Concrebrás e Concrebrás (08012.001227/2002-15)

A Sita-Concrebrás S.A. é uma empresa do Grupo Sirama que detém 99,99\% das ações do capital votante e total da Sita. O Grupo Sirama atua ofertando cimento e cal. A Silcar, empresa controlada integralmente pelo Grupo Votorantim, é o maior acionista da Sirama, com $38,21 \%$ do capital, podendo, inclusive, indicar isoladamente e em conjunto com outros sócios, administradores para 
as empresas do Grupo Sirama. ${ }^{7}$ O segundo maior acionista da Sirama detém $9,2 \%$ do capital da empresa. O Grupo Votorantim já atua indiretamente no mercado de concreto através das participações nas empresas Engemix (25\%) e Supermix (25\%).

A Concrebrás S.A. é uma empresa que pertence ao grupo francês Lafarge e atua na prestação de serviços de concretagem.

As empresas Concrebrás e Sita firmaram um contrato que estabelece a aquisição, por parte da Sita, de estabelecimentos e ativos de concretagem, além da marca "Concrebrás".

Desse modo, a participação do Grupo Votorantim, através da Silcar, na Sirama, confere mais uma forma indireta de participação em uma empresa que atua no mercado de concretagem.

A operação foi apresentada ao SBDC em 22/02/2002, julgada em 10/11/2004 e aprovada sem restrições.

- Cimefor e Geral de Concreto (08012.000720/2002-18)

A Cimefor Comercial Exportadora e Importadora Ltda. (Cimefor) é uma empresa pertencente ao Grupo Votorantim. O Grupo atua na prestação de serviços de concretagem por meio de participação indireta e minoritária nas empresas Supermix (25\%) e Sirama (38\%). Além disso, o Grupo detinha, até a presente operação, 25\% da Engemix, controladora indireta da Geral de Concreto. Especialmente para a realização desta operação, foi criada em janeiro de 2002, a empresa Concrefor, controlada pela Cimefor.

A Geral de Concreto S.A. é prestadora de serviços de concretagem. O controle acionário da Geral de Concreto é detido pela EPGE Participações, que por sua vez é controlada pela Engemix Participações S.A. Além da EPGE, a Engemix controla as empresas Concrelix Engenharia de Concreto Ltda. e Concremaster Concreto Ltda. no setor de produção de concreto. A Engemix é controlada pelo Grupo Rossi (75\%) e pelo Grupo Votorantim (25\%).

A operação trata da aquisição, pela Cimefor, da totalidade das ações da Geral de Concreto, anteriormente detidas pela Engemix.

A operação foi apresentada ao SBDC em 15/01/2002, julgada em 10/11/2004 e aprovada sem restrições.

- Silcar e Sirama (08012.008848/2005-72)

A Silcar Empreendimentos, Comércio e Participações Ltda. (Silcar) é uma holding pertencente integralmente ao Grupo Votorantim, sem atividades operacionais, com participação acionária em diversas empresas do Grupo.

A Sirama Participações, Administração e Transportes Ltda. (Sirama) possui $38 \%$ de seu capital social detido pelo Grupo Votorantim, por intermédio da Silcar. A Sirama, por sua vez, controla diversas empresas, entre elas a Sita Concrebrás S.A., do ramo de serviços de concretagem.

A RV Empreendimentos Ltda. (RV) é um empreendimento de participações sem atividades operacionais pertencente à Família Vieira. A empresa Polimix Concreto Ltda. pertence 100\% à RV.

\footnotetext{
${ }^{7}$ A participação da Silcar (Votorantim) na Sirama foi submetida e aprovada pelo SBDC segundo A.C. no 08000.000588/1997-64.
} 
A operação trata-se da aquisição, pela Silcar, de $25 \%$ das quotas detidas pela RV no capital social da Polimix Concreto. ${ }^{8}$

A operação foi apresentada ao SBDC em 10/10/2005, julgada em 24/07/2008 e aprovada condicionada à celebração de um Termo de Compromisso de Desempenho. Segundo o Termo, a Silcar obrigou-se a não eleger qualquer diretor da Polimix, não participar de qualquer reunião de sócios que vise à fixação de orientação dos negócios de prestação de serviços de concretagem, não interferir, opinar, participar, solicitar ou ter acesso à política comercial dos negócios da Polimix. Além disso, a Silcar e a Família Vieira se comprometeram a promover as alterações societárias necessárias para que os ativos relacionados à prestação de serviços de concretagem nos mercados relevantes de Curitiba/PR, Maringá/PR, Criciúma/SC, Lages/SC, Florianópolis/SC, Camboriú/SC, Blumenau/SC, Joinville/SC e Guaramirim/SC sejam transferidos para uma sociedade a ser constituída apenas pela Família Vieira, que terá $100 \%$ do seu capital.

\section{Aplicação do MHHI para o setor de produção de concreto da região Sul do Brasil}

O cálculo do MHHI para o setor de produção concreto da região do Brasil foi realizado com dados públicos obtidos dos processos já analisados e julgados pelos órgãos de defesa da concorrência. Os dados encontram-se disponíveis no site do CADE. ${ }^{9}$ Para determinar o grau de controle dos proprietários foram utilizados o índice de Banzhaf, descrito na seção 2.4 deste trabalho, e um algoritmo disponível online para o cálculo ${ }^{10}$.

A análise dos efeitos de um ato de concentração pressupõe a identificação do chamado mercado relevante. A esse respeito, cita-se Farina et al. (2008, p.97-98):

“O mercado relevante é constituído pelo conjunto de produtos e de áreas geográficas nas quais o poder de mercado pode ser exercido. (...) A definição de duas dimensões do mercado relevante - a dimensão produto e a dimensão geográfica - é um recurso didático que ajuda a sistematizar os procedimentos de instrução. Em termos analíticos, o conceito subjacente a essas dimensões é o de substituição pelo lado da demanda: se o consumidor percebe que um determinado produto ofertado em certo lugar está "caro", pode (i) procurar outro produto que tenha propriedades semelhantes, ou (ii) procurar produto fisicamente idêntico em outro lugar."

Neste trabalho, o mercado relevante do produto é o concreto dosado em central. Para a dimensão geográfica foram utilizados os mercados relevantes definidos nas análises do SBDC. As empresas fornecedoras de concreto não podem estar distantes dos locais das construções, pois existe uma limitação de duas horas para a aplicação do concreto antes que entre em fase de endurecimento. A região de atuação se limita, portanto, a um raio de 25 a 50

\footnotetext{
${ }^{8}$ Neste mesmo processo foram avaliadas outras operações envolvendo a Família Vieira e o Grupo Votorantim: uma operação no mercado de produção de concreto, mas fora da região Sul do Brasil, e outra envolvendo o mercado de cimento, ambas fora do escopo deste trabalho.

${ }^{9}$ http: / / www . cade.gov.br/Default .aspx?a8889b6caa60b241d345d069fc.

${ }^{10}$ http : / / www. warwick. ac.uk/ ecaae/.
} 
quilômetros de distância da unidade concreteira. Por esse motivo, o SBDC considera os limites municipais e os municípios contíguos, distantes a menos de 50 quilômetros, para a dimensão geográfica do mercado relevante dos serviços de concretagem.

A Tabela 2 apresenta os mercados relevantes definidos pelo SBDC para cada ato de concentração aqui analisado, considerando apenas os mercados da região Sul do Brasil. ${ }^{11,12}$

Tabela 2: Mercados relevantes geográficos definidos pelo SBDC

\begin{tabular}{|c|c|}
\hline Processo (Operação) & Mercado Relevante Geográfico \\
\hline 08012.007680/1998-51 (1) & Paraná, Santa Catarina e Rio Grande do Sul \\
\hline 08012.007704/1999-07 (2) & Curitiba/PR, Florianópolis/SC \\
\hline $08012.001227 / 2002-15(3)$ & $\begin{array}{l}\text { Curitiba/PR, Maringá/PR, Foz do Iguaçu/PR, } \\
\text { Ponta Grossa/PR, Paranágua/PR, Cambé/PR, Flo- } \\
\text { rianópolis/SC, Balneário Camboriú/SC, Blume- } \\
\text { nau/SC, Joinville/SC, Porto Alegre/RS, São Leo- } \\
\text { poldo/RS, Caxias do Sul/RS. }\end{array}$ \\
\hline $08012.000720 / 2002-18(4)$ & $\begin{array}{l}\text { Curitiba/PR, Maringá/PR, Foz do Iguaçu/PR, } \\
\text { Ponta Grossa/PR, Paranágua/PR, Cambé/PR, Flo- } \\
\text { rianópolis/SC, Balneário Camboriú/SC, Blume- } \\
\text { nau/SC, Joinville/SC, Porto Alegre/RS, São Leo- } \\
\text { poldo/RS, Caxias do Sul/RS. }\end{array}$ \\
\hline 08012.008848/2005-72(5) & $\begin{array}{l}\text { Curitiba/PR, Maringá/PR, Foz do Iguaçu/PR, Lon- } \\
\text { drina/PR, Florianópolis/SC, Balneário Cambo- } \\
\text { riú/SC, Blumenau/SC, Joinville/SC, Criciúma/SC, } \\
\text { Lages/SC, Guaramirim/SC, Porto Alegre/RS }\end{array}$ \\
\hline
\end{tabular}

Foram incluídos na tabela apenas os mercados relevantes geográficos definidos pelo SBDC que pertencem à região Sul do Brasil.

Ao longo do tempo, houve uma mudança na definição do mercado relevante geográfico da prestação de serviços de concretagem pelo SBDC, passando do nível estadual para o nível municipal. Devido às especificidades do produto, conforme já apresentadas, o nível municipal é o mais adequado para análise.

Definidos os mercados relevantes geográficos, os resultados para o $H H I$, $\triangle M H H I$ e $M H H I$ encontram-se na Tabela 3 a seguir.

Os resultados da Tabela 3 nos mostram que, ao utilizarmos o HHI como medida de concentração de mercado quando existem participações minoritárias entre firmas rivais, subestimamos o valor do índice e, consequentemente, os efeitos dessas participações sobre a concorrência. Na maior parte das vezes, o aumento no $H H I$ decorrente da inclusão dessas participações minoritárias no cálculo, mostrado pelo $\triangle M H H I$, é bastante significativo, tanto mais quanto mais ligações estão presentes. Por outro lado, se considerássemos essas ligações estruturais como se fossem fusões completas o índice seria superestimado.

As autoridades de defesa da concorrência no Brasil, assim como o Departa-

\footnotetext{
${ }^{11}$ Foram incluídos na tabela apenas os mercados relevantes geográficos definidos pelo SBDC que pertencem à região Sul do Brasil.

${ }^{12}$ Ao longo do tempo, houve uma mudança na definição do mercado relevante geográfico da prestação de serviços de concretagem pelo SBDC, passando do nível estadual para o nível municipal. Devido às especificidades do produto, conforme já apresentadas, o nível municipal é o mais adequado para análise.
} 


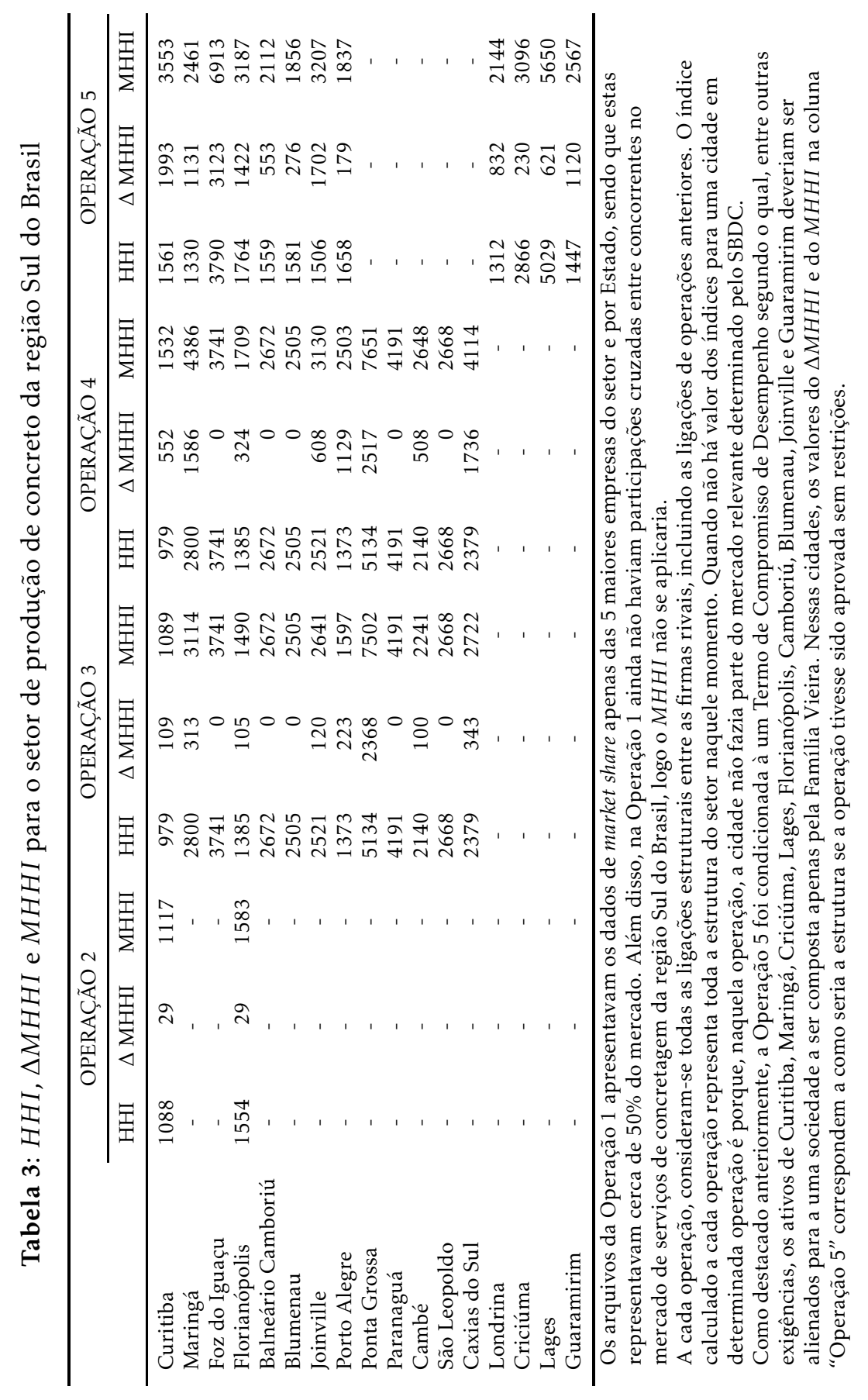


mento de Justiça dos Estados Unidos $(\mathrm{DOJ})^{13}{ }^{13}$, consideram que mercados com índice entre 1.000 e 1.800 são moderadamente concentrados e mercados com índice acima de 1.800 são concentrados. Além disso, atos de concentração que resultem em aumentos do HHI maiores que 100 devem causar preocupação e ser analisados com cautela pelas autoridades antitruste.

Na cidade de Ponta Grossa, por exemplo, que foi apresentada como mercado relevante das operações 3 e 4, na data das operações, operavam apenas duas empresas, Supermix e Concrebrás, nas quais o Grupo Votorantim detém $25 \%$ e $38,2 \%$ de participação, respectivamente (por intermédio das empresas Itaú e Silcar). Obviamente, devido ao fato de apenas duas empresas atuarem no mercado, o HHI já se mostra bastante elevado. Além disso, a ligação estrutural entre essas únicas firmas ofertantes do produto no mercado aumenta o índice em mais de 2.300 pontos.

No que se refere à Operação 3, a SEAE (Secretaria de Acompanhamento Econômico) não se manifestou em relação à presença de participações cruzadas entre os agentes do mercado, mas tanto a SDE (Secretaria de Direito Econômico) como o conselheiro relator do caso atentaram para os possíveis efeitos anticompetitivos dessas ligações. Por outro lado, fatores como a presença de "várias outras concreteiras independentes", "inexistência de barreiras significativas à entrada", "baixos custos de criação ou de manutenção desse tipo de empresa", "possibilidade de produção do concreto na própria obra pelo construtor" e "inexistência de fidelidade à marca" fizeram com que a operação fosse aprovada sem restrições.

Quanto à Operação 4, não foram consideradas nas análises do SBDC a presença de participações minoritárias entre as requerentes. O conselheiro relator em seu voto concluiu que "apesar de a operação gerar altas concentrações em alguns mercados", as empresas não terão condições de exercer seu poder de mercado após a operação, devido ao fato de as barreiras à entrada serem baixas, a técnica de produção ser simples e os custos de entrada e saída serem relativamente baixos, de modo que a operação foi aprovada sem restrições.

Outro exemplo interessante refere-se ao mercado de Curitiba. Na data da última operação analisada (Operação 5), atuavam no mercado 12 empresas, incluindo as empresas Engemix, Concrebrás, Supermix e Polimix. O Grupo Votorantim controla integralmente a Engemix e detém participação de 38,2\% na Concrebrás, $25 \%$ na Supermix e $25 \%$ na Polimix. Quando essas participações cruzadas entre as rivais são levadas em consideração no cálculo, o aumento no índice provocado por essas participações $(\triangle M H H I=1.993)$ é maior, em termos absolutos, do que o valor do índice quando não consideradas ( $H H I$ $=1.561)$, de modo que o índice total $(M H H I=3.553)$ mais que dobra quando consideramos as participações no cálculo.

Em Blumenau, na data da última operação, os efeitos mostraram-se relativamente pequenos quando comparado às outras cidades. Isso ocorre devido ao fato de que atuam 9 empresas no mercado, das quais apenas 2 tem ligações estruturais: Concrebrás (38\% Votorantim) e Engemix (100\% Votorantim), cada uma com 14,9\% e 2\% de market share, respectivamente. Embora o market share da Engemix seja pequeno, a ligação estrutural garantiu um aumento de 276 pontos no índice.

\footnotetext{
${ }^{13}$ Vide orientação disponível em http: / / www. justice.gov/atr/public/testimony / hhi.htm. Página visitada em 08/06/2010.
} 
Cabe ressaltar que, para o mercado relevante de Foz do Iguaçu, a Operação 5 não sofreu restrições devido ao fato de que, pouco antes da data do julgamento desta operação, o CADE não aprovou uma outra operação que impactava nesse mercado. Trata-se da compra de alguns ativos de concretagem da Holcim pela Engemix, ${ }^{14}$ operação em que um dos mercados relevantes era Foz do Iguaçu, onde atuavam apenas as empresas Holcim e Polimix e a Engemix compraria a totalidade dos ativos da Holcim. Esta operação estava em análise no SBDC simultaneamente à Operação 5, de modo que, quando o CADE não aprovou a compra dos ativos da Holcim pela Engemix, o mercado de Foz do Iguaçu passou a não ser objeto da análise da operação entre Engemix e Polimix (Operação 5).

Os números mostram que a parcela do índice que mensura os efeitos sobre a concorrência de participação minoritária em firma rival não pode ser desprezada, pois representa parcela importante do valor total do índice, mesmo quando as empresas com ligação estrutural têm uma porção pequena do market share. A parcela do índice que mensura o efeito da participação em firma rival será tanto maior quanto maiores forem os market shares das empresas ligadas e o tamanho das ligações, comparados com as participações dos demais acionistas.

\section{Considerações finais}

Através do cálculo do MHHI para diversas fases de reestruturação societária, pode-se avaliar a evolução do processo de concentração em um determinado mercado levando em consideração participações minoritárias entre as firmas rivais. O setor de produção de concreto da região Sul do Brasil, que apresenta diversas ligações estruturais entre as firmas rivais, foi utilizado como modelo para o estudo.

A aplicação do HHI e do $M H H I$ como índices de concentração mostrou que os resultados de análises de atos de concentração podem ser significantemente diferentes na presença de participações minoritárias entre rivais. A utilização do HHI considerando que as firmas ligadas são totalmente independentes subestima o índice, enquanto a aplicação do índice considerando as firmas ligadas como se fossem apenas uma superestima o índice.

O tamanho do efeito de participação minoritária em firma rival sobre a concorrência depende, principalmente, de dois fatores: dos market shares das firmas ligadas e do poder de controle que a firma adquirente tem sobre a firma adquirida. Quanto maiores forem esses fatores, maiores serão os prejuízos à concorrência.

O MHHI considera esses fatores, e se apresenta como método mais adequado para a avaliação dos prejuízos à concorrência quando estão presentes participações minoritárias entre firmas rivais.

Da mesma forma que o $H H I$, o $M H H I$ não é suficiente para determinar que haverá exercício de poder de mercado, de modo que fatores como barreiras à entrada, rivalidade, elasticidade-preço da demanda, entre outros, devem ser considerados na análise. No entanto, o cálculo de índices de concentração contribui sobremaneira para avaliação dos efeitos anticompetitivos em atos de concentração.

\footnotetext{
${ }^{14}$ AC n 08012.009419/2004-31, julgado em 19/03/2008.
} 
O cálculo de índices de concentração tem sido utilizado pelas autoridades de defesa da concorrência como um primeiro filtro para auxiliar na escolha dos mercados que devem ser estudados mais detalhadamente. Considerar as firmas com participações cruzadas como se fossem apenas uma e calcular o HHI não acarreta problemas para a análise, uma vez que o índice seria subestimado e a análise passaria para o estágio posterior se houvesse indício de probabilidade do exercício de poder de mercado. Por outro lado, se a autoridade considerar que as firmas ligadas são totalmente independentes e calcular o HHI, o índice seria subestimado, e uma operação com o condão de causar possíveis danos à concorrência pode não ser analisada mais rigorosamente.

Nesse caso, alguém poderia argumentar que na presença de participações minoritárias basta considerar as empresas como se fossem uma e, se o índice apontar para probabilidade do exercício do poder de mercado, passa-se para a etapa posterior da analise. No entanto, a relação custo-benefício de se utilizar o $M H H I$ vem do fato de que a autoridade pode obter facilmente os dados para a mensuração do poder de mercado e obter assim um índice mais acurado.

No caso específico das operações analisadas neste estudo, não se pode obter as informações completas acerca do poder de controle de cada um dos proprietários e, como alternativa, utilizou-se o índice de poder de Banzhaf, assim como Trivieri (2005) para o setor bancário italiano. Acreditamos que, mesmo com essa limitação, o estudo contribui positivamente, ao lançar luz sobre as substanciais diferenças em termos quantitativos em razão de índices que levam em consideração diferentes pontos. Ademais, trata-se apenas de uma possível maneira de se aplicar o MHHI. Conforme mencionado, a autoridade de defesa da concorrência que irá utilizar o índice pode perguntar sobre o processo de decisão da empresa e incorporar essa informação no cálculo do índice.

Quanto aos possíveis trabalhos futuros, acreditamos que explorar os efeitos do contato multimercado poderia complementar o estudo, uma vez que esse contato multimercado pode alterar as estratégias competitivas das firmas. Algumas das empresas analisadas neste estudo também concorrem nos mercados de cimento e cal, por exemplo.

\section{Agradecimentos}

As autoras gostariam de agradecer o apoio da Fapesp (Fundação de Amparo à Pesquisa do Estado de São Paulo) para realização deste trabalho.

\section{Referências Bibliográficas}

Areeda, P. \& Turner, D. F. (1980), Antitrust Law: An Analysis of Antitrust Principles and their Application, 1 edn, Little, Brown \& Company.

Bresnahan, T. F. \& Salop, S. C. (1986), 'Quantifying the competitive effects of production joint ventures', International Journal of Industrial Organization $4(2), 155-175$.

Church, J. \& Ware, R. (2000), Industrial Organization: A Strategic Approach, 1 edn, Irwin McGraw-Hill.

Cowling, K. \& Waterson, M. (1976), 'Price-cost margins and market structure', Economica 43(171), 267-274. 
Dubrow, J. B. (2001), 'Challenging the economic incentives analysis of competitive effects in acquisitions of passive minority equity interests', Antitrust Law Journal 69(1), 113-145.

Ezrachi, A. \& Gilo, D. (2006), 'Challenging the economic incentives analysis of competitive effects in acquisitions of passive minority equity interests', Oxford Journal of Legal Studies 26(2), 327-349.

Farina, E. M. M. Q. \& Nunes, R. (2006), A operação de uma política moderna de controle de fusões no brasil, in J. Velloso, ed., 'Por uma moderna política de competição: ampliando as bases do alto crescimento no Brasil', Vol. 1, José Olympio.

Farina, E. M. M. Q., Nunes, R. \& Farina, T. M. (2008), Comportamento dos preços e identificação do mercado relevante: o caso cvrd, in C. Mattos, ed., 'A revolução do antitruste no Brasil 2: a teoria econômica aplicada a casos concretos', Singular.

Farrell, J. \& Shapiro, C. (1990), 'Horizontal mergers: An equilibrium analysis', The American Economic Review 80(1), 107-126.

Leech, D. (2002), 'An empirical comparison of the performance of classical power indices', Political Studies 50, 1-22.

O’Brien, D. P. \& Salop, S. C. (2000), 'Competitive effects of partial ownership: financial interest and corporate control', Antitrust Law Journal 67, 559-614.

Organization for Economic Co-operation and Development, O. (2008), 'Antitrust issues involving minority shareholdings and interlocking directorates', Background Note.

Reynolds, R. J. \& Snapp, B. R. (1986), 'The competitive effects of partial equity interests and joint ventures', International Journal of Industrial Organization $67,141-153$.

Trivieri, F. (2005), Proprietà e controllo delle banche italiane, 1 edn, Rubentino. 